\title{
Detection of Hepatitis B Antigen in The Dental Instruments Used in Public Dental Clinics in Duhok Province, kurdistan Region/ Iraq
}

Ali Yahya Saeed

BDS, MSc, PhD(Assist Prof)

Saeed Ali Barwari (Lec)

$\mathrm{BDS}, \mathrm{MSc}, \mathrm{PhD}$
Department of Biology

College of Science, University of Duhok

Department of Periodontology

College of Dentistry, University of Duhok

\begin{abstract}
الخلاصة

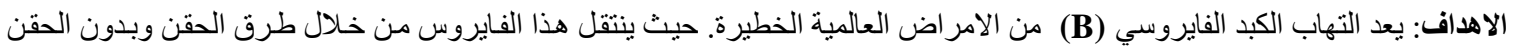

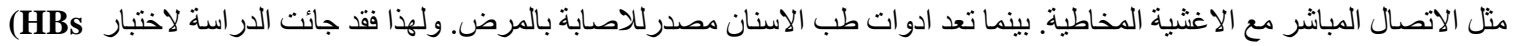

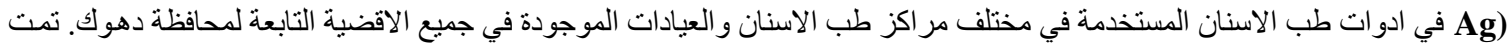

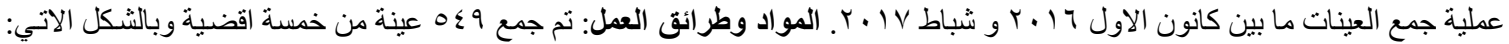

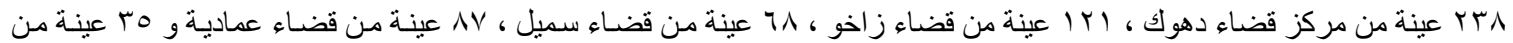

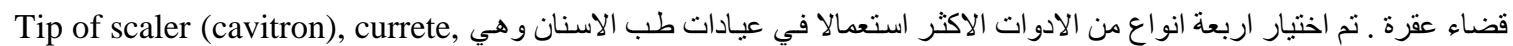

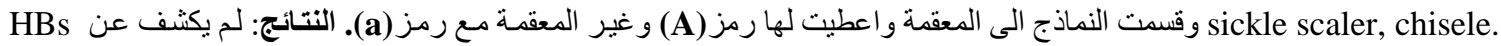

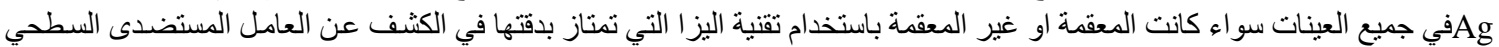

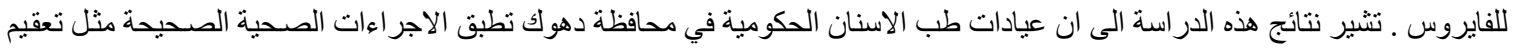

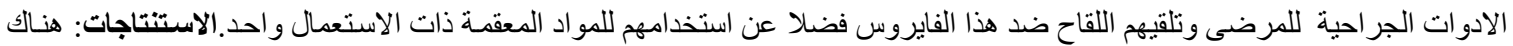

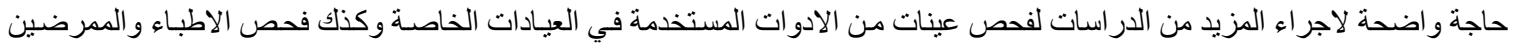

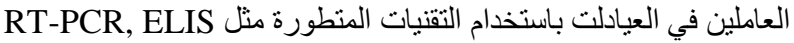

\begin{abstract}
Aims: Hepatitis B virus infection is a global health hazard. The virus can be transmitted by both parenteral and non- parenteral methods such as direct contact with mucus membrane. Dental instruments can be the source of infection, therefore this study was conducted to detect HBs Ag in dental instruments used in the different public dental centers and clinics in Duhok governorate. Sampling process was from December 2016 to January 2017. Materials and Methods: A total of 549 samples were collected from five different districts as follow: 238 samples from center of Duhok, 121 samples from Zakho, 87 samples from Amedi, 68 samples from Sumail and 35 samples from Aqre. Four different commonly used dental instruments were chose namely: Scaler tips, curette, sickle and chisele. The samples divided into sterilized and used using capital A letter for sterilized and small a letter for used samples. Results: No HBs Ag was detected in all tested samples both sterilized and non- sterilized samples by ELISA technique. The results of the present study indicated to the proper hygienic precautions implemented in public dental centers and clinics as well as to the effectiveness of anti-HBV vaccine that almost all dentists had been received prior working. Conclusions: Further studies are required to cover private dental instruments as well as dentists and assistant technicians using both ELISA and RT-PCR techniques.
\end{abstract}

Key words: Hepatitis B Antigen, Dental Instruments, periodontal instruments.

Saeed AY, Barwari SA. Detection of Hepatitis B Antigen in The Dental Instruments Used in Public Dental Clinics in Duhok Province, kurdistan Region/ Iraq. .Al-Rafidain Dent J. 2018,18(1):42-47.

Received: 8/7/2018 Sent to Referees: 10/7/2018 Accepted for Publication: 11/11/2018 


\section{INTRODUCTION}

Among infectious diseases two viral infections namely human immunodeficiency virus (HIV) and hepatitis B virus have common features in routes of infections, chronicity and major public health concern in both developing and developed countries. In the point of virulence, HBV seems to be more virulence than HIV because more than 350 million people in the world are chronic carrier of $\mathrm{HBV}$ compared to 35 million peoples carriers of HIV ${ }^{(1,2)}$.

According to the World Health Organization (WHO), there are more than 50 million cases of acute hepatitis infections annually ${ }^{(3,4)}$ with $5-10 \%$ of adults and up to $90 \%$ of infants becoming chronically infected ${ }^{(5)}$.Hepatitis $B$ virus is the tenth cause of death globally which causes 500,000 to 1.2 million death per year due to chronic hepatitis, cirrhosis and hepatocellular carcinoma ${ }^{(3,4)}$. Based on the prevalence of $\mathrm{HBV}$ chronic carriers ( individuals positive for hepatitis B surface antigen) among adults in the general population, countries are classified as having low endemicity $<2 \%$, intermediate endemicity $2-8 \%$ or high endemicity $>8 \%$ (6). Iraq is considered to be of moderate endemicity for $\mathrm{HBV}$ with a rate of $3 \%{ }^{(7)}$. Most serological studies carried out in the different parts of the world have found a higher prevalence of HBV infection among dentists, especially among surgical specialties (oral, maxillofacial and periodontists) compared to the general population ${ }^{(8-10)}$.

Most of the studies were carried out in pre-vaccination era, therefore, the picture of HBV prevalence among dentists still a matter of debate. Medical devices like dental instruments have also associated with HBV transmission ${ }^{(11)}$. Most positive cases of HBV in our area have no history to the common known routes of infection except their visiting to the dentistry clinics, so most people believe that the main source of $\mathrm{HBV}$ infections is the contaminated dental instruments. In order to decipher this public concept on dentists and dentistry clinics and spot whether they are guilty or innocent, this study was performed to detect hepatitis B surface antigen in the dental instruments used in both private and public dentistry clinics in Duhok Province.

\section{MATERIALS AND METHODS}

\section{Sampling method A}

total of 549 samples were collected from five different districts of Duhok Province as follow: 238 samples from 16 public dentistry centers and clinics in the center of Duhok City, 121 samples from five different clinics in Zakho District, 68 samples from three clinics in Sumail District, 87 samples from Amedi District 
and 35 samples from Aqre District. Samples were collected from December, 2016 to February, 2017. From each dental clinic and center four different instruments were chosed namely tip of scaler, curette, sickle and chisele both sterilized and used.
Samples were coded as follow: A1, A2, A3 and A4 for sterilized scaler, curette, sickle and chisele respectively while a1, a2, a3 and a4 for the same instruments but after their using (Table 1).

Table (1): Types of collected samples

\begin{tabular}{cccc}
\hline \multicolumn{2}{c}{ Sterilzed instruments } & & Used instruments \\
\hline Code & Name of instrument & Code & Name of instrument \\
A1 & Tip of scaler & a1 & Tip of scaler \\
A2 & Currete & a2 & Currete \\
A3 & Sickle & a3 & Sickle \\
A4 & Chisele & a4 & Chisele \\
\hline
\end{tabular}

Each sample was shaked for few seconds in eppendorf container contained 1 $\mathrm{ml}$ of sterile normal saline and transferred in a cool box into Virology laboratory of Public health department and kept in deep freezer for ELISA test.

\section{Serological test}

All samples were thawed and tested for $\mathrm{HB}$ surface antigen ( $\mathrm{HBs} \mathrm{Ag}$ ) by using ELISA HBs Ag kit (Fortress diagnostics, UK) following the instructions of the company. The threshold sensitivity of the test is $0.5 \mathrm{ng} / \mathrm{ml}$. In order to verify that the kit is working with contaminated fluids rather than human body fluids, two fold dilutions were prepared from known positive serum samples using sterile normal saline as a diluent, then tested for HBs Antigen.

\section{RESULTS}

All tested samples from all dentistry public centers and clinics were negative for HBs Ag as shown in Table 2.

Table (2): Results of ELISA HB surface antigen test

\begin{tabular}{cccc}
\hline Destrict & Dentistry clinic & Number of samples & Results of ELISA test \\
\hline Duhok & 16 & 238 & 0 \\
Zakho & 5 & 121 & 0 \\
Sumail & 3 & 68 & 0 \\
Amedi & 2 & 87 & 0 \\
Aqre & 1 & 35 & 0 \\
Total & 27 & 549 & 0 \\
\hline
\end{tabular}


While Eight two fold diluted positive serum sample tubes corresponding to $1 / 2$,
$1 / 4,1 / 8,1 / 16,1 / 32,1 / 64,1 / 128,1 / 256$ gave positive for HBs antigen as shown in Table 3.

Table (3): Results of two fold diluted known HBs Ag positive serum sample

\begin{tabular}{lllllllll}
\hline Tube & 1 & 2 & 3 & 4 & 5 & 6 & 7 & 8 \\
Dilution & $1 / 2$ & $1 / 4$ & $1 / 8$ & $1 / 16$ & $1 / 32$ & $1 / 64$ & $1 / 128$ & $1 / 256$ \\
\hline
\end{tabular}

\section{DISCUSSION}

Nowadays, most of people believe that the dental clinics constitute the main source of hepatitis B virus infection because most of the infected individuals have no known history of exposure to the parenteral routes of transmission except their visiting to the dental clinics. Moreover, there are a lot of papers carried out in the different parts of the world indicating to the role of dental instruments in the transmission of $\mathrm{HBV}$ among people, therefore this is the first study to be carried out in the area to test for HBV in both sterilized and used dental equipment in the different public dental centers and clinics in Duhok Province.

In the present study, no hepatitis B surface antigen was detected among 549 samples of commonly used instruments in 27 different public dental centers and clinics in Duhok Province. Al-Sharifi et al ${ }^{(12)}$ in Iran found $2 \%$ of apparently sterilized dental instruments were positive for $\mathrm{HBs} \mathrm{Ag}$, while no HBs Ag was detected in 365 dental instruments sterilized by autoclave and two samples out of $430 \quad(0.46 \%)$ dental instruments sterilized by $2 \%$ glutaraldehyde were positive for $\mathrm{HB} \mathrm{s} \mathrm{Ag}$ in China by Linfu et al ${ }^{(13)}$. Al-Hijazi ${ }^{(14)}$ found that 2 $(4.08 \%)$ out of 67 dentists were positive for HBs Ag and 45 (91.8\%) of them had antiHBs Ag antibodies. In another study carried out in Duhok Province by Hussein et al ${ }^{(15)}$ found $0.2 \%$ of the blood donors were positive for HBs Ag similar to that found by Al-Shilfy et al. ${ }^{(16)}$ who found $0.12 \%$ of the blood donors in Missan governorate were positive for $\mathrm{HBs} \mathrm{Ag}$. In another study carried out in Nineveh governorate by Salim and Abdullah ${ }^{(17)}$ found that $39.77 \%$ of the blood donors were positive for HBs Ag. Tarky et al. (7) found that the national prevalence rate of HBs Ag in Iraq was 1.6\%. The results of this study clearly indicate the proper hygienic measurements precautions followed by all dental clinics using of sterilizing instruments, disposable masks and gloves as well as almost of the dentists were received full anti HBV vaccine. In order to verify that ELISA kit is also working with samples rather than human serum fluids we made two fold dilution of 
known HBs Ag positive serum and tested for HBs Ag by ELISA kit and all dilutions from $1 / 2$ to $1 / 256$ gave positive for $\mathrm{HBs} \mathrm{Ag}$. Upon our results, the level of HBs $\mathrm{Ag}$ in dental instruments is absent or present in very low concentration under the threshold of ELISA technique because we expected to find out positive cases of $\mathrm{HBs} \mathrm{Ag}$ in the instruments of public clinics rather than those of private clinics as many people believe that hygienic and proper care are less in public dental clinics compared to those serviced in the private dental clinics.

\section{CONCLUSIONS}

Although the results of this study are encouraging and support that dentists and dental instruments are not the main source of infection of HBs $\mathrm{Ag}$, but another sources should also be studied like hair dressing, cosmetic saloons and barbers instruments. Further studies are required like investigation of HBV by RT-PCR technique among dentists and assistant technicians, as well as instruments used in private dental clinics.

\section{REFERENCES}

1-Previsani, N and Lavanchy, D. (2002). Hepatitis B.WHO/CDS/CSR/LYO/2002: Hepatitis B, World Health Organization, Geneva.

2- Perz, J.F., Armstrong, G.L., Farrington, L.A., Hutin, Y.J and Bell, B.P. The contributions of hepatitis $B$ virus and hepatitis $\mathrm{C}$ virus infections to cirrhosis and primary liver cancer worldwide. J Hepa-tol, 2006:45, 529-538.

3- WHO. The World Health Report. Geneva: WHO, 1997

4- WHO. Hepatitis B Fact Sheet No. 204 (Revised October 2000). WHO web site, 2000.

5-Merican, I., Guan, R., Amarapuka, D. Chronic hepatitis B virus infection in Asian countries. J Gastroenterol Hepatol , 2000:15(12), 1356-1361.

6-World Journal of Gastroente WHO: Hepatitis B surface Ag assays; operational characteristics. Phase1.Report, World Health Organization, 2004, (WHO/BCT/BTS/01.4). 7-Tarky, A.A.M., Akram, W., Al-Naaimi, A.S., Omer, A.R. Epidemiology of viral hepatitis B and V in Iraq. A national survey 2005-2006. Zanco J Med Sci, 2013:17(1), 370-380.

8-Olubuyide, I.O., Ola, S.O., Aliyu, B. Hepatitis $\mathrm{B}$ and $\mathrm{C}$ in doctors and dentists in Nigeria. QJM, 1997:90(6), 417-422.

9-Gillcrist, J.A. Hepatitis viruses A, B, C, D, E and G: implications for dental personnel. J Am Dent Assoc, 1990:130(4), 509-520.

10-Martins, A.M., Barreto, S.M. Hepatitis B vaccination among dentists surgeons. Rev Saude Publica, 2003:37(3,333-338.

11-Anonymous, 2003b. Occupation risk for hepatitis. Available at http// 
www.hcvets.com/data/transmission/methods /dental.htm.

12-Sharifi-Mood, B., Rashidi, H., Khalili, M., Sanei-Moghaddam, S.Which Equipment are more infected with hepatitis B virus, Dental equipment or Endoscope? J Med Sci, 2006:6(3), 502-504.

13-Lin-fu, Z., Hai-Hong, Z., Jun, L., Min-Jun, H.V., Feng, C., Zhi, C. Surveillance of viral contamination of invasive medical instruments in dentistry. Journal of Zheijiang University SCIENCEB, 2006:17(1), 38-42.

14-Al-Hijazi, A.Y. Seroprevalence of hepatitis B infection among dental professionals. J College Dentistry, 2005:17(1), 38-42.
15-Hussein, N.F., Haj, S.M., Almizori, L.A., Taha, A.A. The prevalence of hepatitis B and $\mathrm{C}$ viruses amiong blood donors attending blood bank in Duhok, Kurdistan Region/Iraq. Inf J Infect, 2017:4(1).

16-Alhilfi, H.S.Q., Alhashimi, R.A.H., Alsaad, R. K. A. Seroprevalence of hepatitis $\mathrm{B}$ and $\mathrm{C}$ viruses amonmg blood donors in Missan governorate/Iraq. International journal of innovation and applied studies, 2015:11(3), 816-820.

17-Salim, R.W and Abdullah, B.A. The prevalence of hepatitis $B$ virus in high risk groups in Nineveh governorate/ Iraq. Baghdad Science Journal, 2014: 11(2), 888893. 